\title{
Notícia: Professora Silvia Lane
}

\author{
Ana Mercês Bahia Bock ${ }^{1}$ \\ Maria da Graça M. Gonçalves \\ Pontifícia Universidade de São Paulo
}

\section{News: Professor Silvia Lane}

Para nós, alunas da Professora Silvia Tatiana Maurer Lane, é uma honra o convite que a revista Psicologia: Teoria e Pesquisa nos fez para ocupar este espaço com uma homenagem. A tarefa é difícil, pela emoção do momento e pela grandiosidade da Professora Sílvia Lane. Corremos o risco das palavras não expressarem nossos sentimentos e o significado que reconhecemos em Sílvia. Mas, vamos tentar, pela satisfação em fazer a merecida homenagem.

A Professora Silvia Lane foi acima de tudo professora:

O professor trabalha para suprimir a figura do aluno enquanto aluno, isto é, o trabalho pedagógico se efetua para fazer com que a figura do estudante desapareça. Para isto, o professor precisa fazer um esforço cotidiano para que seu lugar permaneça vazio, pois seu trabalho é tornar possível o preenchimento desse lugar por todos aqueles que estão excluídos dele e aspiram por ele e pelo qual não poderiam aspirar se já estivesse preenchido por um senhor e mestre (..). A relação professor-aluno é assimétrica e sem diálogo: este se torna possível quando o aluno desaparece e em seu lugar existe um novo professor. O diálogo (...) se torna real quando o trabalho pedagógico termina e o professor encontra-se com o não-aluno, o outro professor, seu igual (...) o lugar do professor está vazio, pois seu ocupante ali se encontra para deixá-lo através de seu próprio trabalho (Chauí, 1980, p. 39).

Na dialética da atividade de ensinar podemos perceber por que Silvia Lane foi acima de tudo uma Professora. Soube como poucas acolher o aluno e entregar-lhe, sem receios, a palavra.

Quando éramos, ainda, estudantes da Faculdade de Psicologia da PUC-SP, Silvia era diretora, função que exerceu de 1971 a 1974, tendo sido a primeira diretora da recém criada Faculdade de Psicologia da PUC-SP, que resultava da junção das Faculdades de Filosofia, Ciências e Letras de São Bento e do Sedes Sapientiae. Nesta época, a Professora Silvia foi responsável por implantar o novo curso e neste processo inovou e incentivou inovações importantes que dariam uma marca para o curso de Psicologia da PUCSP. Os espaços abertos para a voz e os projetos dos alunos, o valor e incentivo às representações estudantis nos órgãos colegiados, a busca constante da articulação da teoria com a prática, o diálogo da diversidade e o compromisso com as camadas pobres da população que não tinham acesso aos serviços de Psicologia compunham, ao lado das teorias e técnicas da Psicologia, um

1 Endereço: Rua Irundiara, 35, São Paulo, SP, Brasil 04535-050. E-mail: anabock@terra.com.br conteúdo de concepção de formação que deveria também ser garantido. Exemplo disso foi uma disciplina que ela criou, "Estudos Livres", na qual a liberdade para estudar significava compromisso com a pesquisa, com o lugar social do psicólogo e a construção de uma Psicologia comprometida com a sociedade, em um exercício da autonomia do aluno, acompanhado pela mestra.

Aprendemos Psicologia Social com a Professora Silvia Lane. Em um primeiro momento, o curso se apresentava conservador, trazendo para o espaço da aula conteúdos, conceitos, teorias e metodologias de influência americana. Mas insatisfeita, Silvia e sua equipe buscavam novas formas de fazer e pensar a Psicologia Social.

A Psicologia Social no Brasil era um 'zero à esquerda', não interferia em nada, não ajudava em nada, quer dizer, era um saber que estava lá, que partia das teorias americanas para explicar a realidade brasileira. Era preciso compreender como o latino-americano singulariza o universal na constituição particular de sua existência (Lane, 2000, p. 4)

E foi esta a tarefa que a Professora Silvia Lane se colocou para uma vida inteira. Incansável pesquisou, publicou, ensinou, aprendeu a pensar e fazer uma nova Psicologia Social.

Em 1982 viajou acompanhada da professora Maria do Carmo Guedes por alguns países da América Latina em um intercâmbio científico que se tornaria um marco na experiência da construção de um conhecimento da América Latina, para e sobre a América Latina.

As experiências dos outros países demonstravam que fazíamos parte de um movimento histórico, no qual a 'crise' e a crítica da Psicologia Social nos levava à procura de novas bases epistemológicas e metodológicas para as pesquisas. Ela também serviu para mostrar o quanto Silvia já havia avançado em seus estudos e que estava no caminho certo para fortalecer $o$ paradigma latino-americano em sedimentação, cujo principal teórico era Martín-Baró. Esse psicólogo social se tornará, a partir de então, um dos parceiros de Silvia, o qual ela chama de mestre, com sua preocupação em perseguir o rigor metodológico e teórico com obsessão, para deselitizar e politizar a Psicologia e deslindar as determinações da alienação, ou seja, a falta de controle das maiorias populares sobre sua própria existência e destino... (Sawaia 2001, p. 44).

As publicações que vão se seguir compondo um total de 42 textos em revistas e livros nacionais e internacionais e 4 
livros (Sawaia,2001) terão esta marca. As iniciativas de busca de um conhecimento da América Latina, a fundação, em 1980, de uma entidade de Psicologia Social para estimular o debate e desenvolver o campo: a Associação Brasileira de Psicologia Social - ABRAPSO, a inquietação teórica que marcará etapas de mudança que compõem um conjunto reconhecido como o pensamento "Laneano" da Escola de São Paulo, as incursões e diálogos com as teorias francesas, americanas, soviéticas e principalmente com o marxismo e as abordagens dialéticas, a proposta de uma Psicologia Comunitária, todo este conjunto de empreitadas buscou contribuir para uma Psicologia que mantivesse com o povo um compromisso de transformação das condições de vida.

Na sua produção teórica dialogou com Osgood, Mead, Skinner, Moscovici e Denise Jodelet, Politzer, Lucien Sève, Lefébvre, Munné, Leontiev, Vigotsky, Agnes Heller, Mario Golder, Martin-Baró, Gonzalez-Rey, Ester Weisenfeld, Euclides Sanches, Maritza Monteiro e Maria Auxiliadora Banchs. Percorreu conceitos de linguagem, grupos, consciência, atividade e identidade, emoção e afetos e criatividade, sempre norteada pela relação homem-sociedade, garantindo uma perspectiva de um sujeito histórico, ativo e social. Garantiu em suas reflexões a dialética subjetividade-objetividade, buscando vencer o pensamento dicotômico de nossos tempos.

Na vida acadêmica pesquisou sempre, mas nunca abandonou a sala de aula, lugar de diálogo com os parceiros-alunos. Foi coordenadora do programa de Pós Graduação em Psicologia Social na PUC-SP (1977 a 1982 e 1987 a 1989); foi diretora do centro de Ciências Humanas na PUC-SP (1981 a 1984), foi representante docente no Conselho de Ensino e Pesquisa da PUC-SP; presidiu a Comissão de Pesquisa do CEPE, foi vice-reitora acadêmica de 1984 a 1987. Foi ainda membro fundador da Associação dos Professores da PUC-SP - APROPUC.

Ocupou a academia com a grandeza dos sábios, sempre atenta para não se deixar levar pela ilusão do poder formal concedido por determinados lugares. Onde esteve, Sílvia foi sempre a professora querida, ocupada por demais com a tarefa de compreender a realidade e o lugar da Psicologia nela e, principalmente, com a discussão da relevância e coerência das ações cotidianas. Essa prioridade guiava suas aulas, suas orientações, suas posições, onde quer que estivesse.
Nós tivemos o privilégio de acompanhar isso de perto. Fizemos nossas teses sob a orientação da Professora Silvia Lane. Fizemos nosso curso de Psicologia encantadas com o projeto de uma Psicologia Social crítica que fosse base de uma Psicologia compromissada; nos tornamos professoras de Psicologia Social, ocupando o lugar que Silvia sempre soube deixar "vazio", no sentido da dialética pedagógica defendida por Chauí. Compusemos, a partir de Silvia Lane, a Equipe de Psicologia Sócio-Histórica da PUC-SP. Escrevemos um livro com sua parceria. Fizemos parte do mesmo Grupo de Trabalho da ANPEPP, na busca do estudo da desigualdade social e do desenvolvimento da Psicologia Sócio-Histórica. Fomos incentivadas por ela a estar nos órgãos de representação dos psicólogos, na busca incessante da construção de um projeto de Psicologia comprometido com as urgências brasileiras e latino-americanas... Que falta sentiremos desta nossa parceira-professora. A Professora Silvia Lane fará enorme falta à Psicologia Social e à Psicologia, como ciência e como profissão.

Mas, nós seguiremos buscando sempre "silvia lanear", que significa ser plural, acolher a diversidade para o diálogo como forma de avançar coletivamente, comprometer-se com a transformação, olhar o mundo da perspectiva do movimento e dos processos, perceber-se histórico e, portanto, saber reconhecer a necessidade da inquietação permanente, escapando da tentação de apegar-se a algum conhecimento tomado como verdade imutável.

\section{Referências}

Chauí, M. S. (1980). Ideologia e Educação. Educação e Sociedade, 5, 24-40.

Lane, S.T.M (2000). Diálogos: Sílvia Lane: a construção de uma Psicologia dialética. PSI Jornal de Psicologia, 122, 4-6.

Sawaia, B. B. (2001). Silvia Lane. Coleção Pioneiros da Psicologia Brasileira. São Paulo: Conselho Federal de Psicologia/Ed. Imago.

\section{ASSINATURA PARA INSTITUIÇÕES}

Assinaturas de Psicologia: Teoria e Pesquisa podem ser solicitadas diretamente à: Secretaria de Divulgação Revista Psicologia: Teoria e Pesquisa Instituto de Psicologia, Universidade de Brasília 70910-900 Brasília, DF, Brasil.

O valor da assinatura anual é $\mathrm{R} \$ 98,00$. Número avulso para assinantes custa $R \$ 26,00$ e número antigo $R \$ 20,00$. Número avulso para não assinantes custa $\mathrm{R} \$ 48,00$. Valores sujeitos a atualização. 